\title{
EQUIDADE E HARMONIZAÇÃO DAS DIFERENÇAS: EXTENSÃO DA CIDADANIA AOS POVOS INDÍGENAS E AFRODESCENDENTES NAS CONSTITUIÇÕES DA BOLÍVIA E DO EQUADOR EM PARALELO À CONSTITUIÇÃO BRASILEIRA
}

\author{
EQUITY AND MATCHING OF DIFFERENCES: EXTENSION OF CITIZENSHIP \\ TO THE INDIGENOUS AND AFRODESCENDANTS IN THE CONSTITUTIONS \\ OF BOLIVIA AND ECUADOR IN PARALLEL TO THE BRAZILIAN \\ CONSTITUTION
}

\section{Allana Elena Mota de Moraes Marques ${ }^{1}$}

RESUMO: O presente artigo objetiva tratar do movimento do Novo Constitucionalismo Democrático Latino-Americano, representado pelas recentes Constituições da Colômbia (1991), da Venezuela (1999), do Equador (2008) e da Bolívia (2009), que fomentou uma gama de avanços principalmente nas esferas política, social, cultural e ambiental, atendendo, em boa parte, às expectativas populares e, portanto, alcançando um elevado grau de legitimidade. Há, assim, um paralelo com a Constituição Brasileira (1988), que, em seu texto, também legaliza direitos relacionados a esses assuntos, destinando um título exclusivamente aos Direitos e Garantias Fundamentais e outro à Ordem Social, por exemplo. Em relação aos direitos sociais, destaca-se o direito de todos à educação, o qual, tanto se configura como um direito e garante, consequentemente, outros direitos, como a liberdade de aprender e o acesso ao ensino de boa qualidade, quanto implica em deveres. Dentre esses, está o referente à busca de políticas públicas que visem uma maior inclusão social, econômica e cultural de povos indígenas e afrodescendentes, grupos étnicos historicamente marginalizados, que, infelizmente, durante o processo de colonização dos países latino-americanos, sofreram com a exploração por povos europeus (que se autodenominaram civilizados e superiores para justificar a dominação sobre o território desses povos e o extermínio quase total de suas culturas e disseminar a ideia de discriminação em relação a essas etnias) e, mesmo após a independência política dessas nações, permanecem marginalizados nas sociedades latino-americanas, especialmente nas quais a desigualdade na distribuição de direitos e renda é mais acentuada. A fim de combater essa lastimável realidade, luta-se para que se assegurem direitos a essas minorias (em sentido de efetivação de direitos), bem como para que a maioria étnica de um país estabeleça, não um relacionamento de mera tolerância em relação às minorias, mas de alteridade, respeito e inclusão desses povos, ou seja, de reconhecimento e, porque não, de admiração da plurinacionalidade e do multiculturalismo. Convém ressaltar que os continentes da

\footnotetext{
I Pós-graduanda (Especialização) em Direito Penal e Processual Penal pela Universidade de Fortaleza (UNIFOR). Bacharela em Direito pela Universidade Federal do Ceará (UFC).
} 
África, que, no caso, forneceu mão de obra à colonização latino-americana, e da Ásia também vivenciaram esse triste cenário de dominação em uma fase posterior do processo colonialista, logo, também estão nessa batalha pela reestruturação dos valores sociais e pelo intercâmbio cultural, firmando, um vínculo com a América Latina. Nessa linha temática, o presente trabalho, através da ênfase aos estudos constitucionais e antropológicos, pretende apontar as inovações proporcionadas pelas Constituições do Equador e da Bolívia (cujas sociedades são marcadamente heterogêneas) e do Brasil e pertinentes à procura pela consolidação da equidade e da harmonização das diferenças sociais, econômicas e culturais desses povos em cada nação. Além disso, tem por objetivo realçar a existência e a importância da identidade e riqueza cultural pertencente a esses grupos, assim como a contribuição de suas culturas para a formação de toda a cultura nacional para que o respeito aos grupos minoritários não seja encarado como um simples dever, mas como um grande e belo ato de cidadania, que é um forte marco da primavera democrática pela qual os países do Novo Constitucionalismo vêm continuamente passando. Para alcançar esse fim, os objetivos específicos são: estudar o mencionado o movimento e os fatores históricos que contribuíram para a insuficiência de direitos constitucionais de indígenas e afrodescendentes na América Latina e para a consequente batalha por esses direitos, passando pela evolução das dimensões dos direitos fundamentais; constatada a necessidade de consagração constitucional de direitos para esses povos, compreender qual o vínculo com as ideias de equidade, harmonização das diferenças e cidadania; e selecionar inovações trazidas pelas Constituições da Bolívia, Equador e Brasil em relação a esses grupos. No tocante à Metodologia, emprega-se pesquisa qualitativa bibliográfica; de forma que alguns doutrinadores basilares foram Afonso; Magalhães, Pastor; Dalmáu, e Wolkmer; Fagundes; e legislativa preponderantemente, assim como exploratória, descritiva e pura. Concluiu-se que as Constituições da Bolívia e do Equador muito progrediram no sentido de se promover a equidade e a harmonização das diferenças dos indígenas e afrodescendentes, possivelmente ainda mais que a Constituição brasileira, e que é necessário que haja concretude desses direitos por meio de políticas públicas que proporcionem a extensão de cidadania a todos e por meio da conscientização de toda a comunidade nacional de que a unidade nacional é composta por todos os grupos étnicos.

Palavras-chaves: Novo Constitucionalismo Democrático Latino-Americano. Inclusão das minorias. Equador. Bolívia. Brasil.

ABSTRACT: Movement of New Democratic Constitutionalism Latin American, represented by recent Constitutions of Colombia (1991), Venezuela (1999), Ecuador (2008) and Bolivia (2009), fostered a range of developments mainly in the political, social, cultural and environmental, meeting popular expectations, and hence, achieving a high degree of legitimacy. There is, thus, a parallel to the Brazilian Constitution (1988), that, in its text, also legalizes rights related to these issues, a title destined exclusively to the Fundamental Rights and Guarantees and other to Social Order, for example. In relation to social rights, we highlight the right of everyone to education, which is configured as both a right and therefore guarantees 
other rights such as the freedom to learn and access to education of good quality, as implies duties. Among these, there is the referent to the search for public policies aimed at greater social, economic and cultural inclusion of indigenous peoples and Afro-descendants, historically marginalized ethnic groups, who, unfortunately, during the process of colonization of Latin American countries, suffered from exploitation by European peoples (who called themselves civilized and superior to justify the domination of the territory of these peoples and the almost total extermination of their cultures, and to disseminate the idea of discrimination against these ethnic groups), and even after political independence of these nations, they remain marginalized in Latin American societies, especially where the inequality in the distribution of rights and income is more pronounced. In order to combat this unfortunate reality, there is the fight to ensure these rights for these groups (in the sense of realization of rights) and that the ethnic majority of a country establishes, not one a relationship of a mere tolerance towards these groups, but of otherness, respect and inclusion of these people, that is, recognition and, why not, admiration to plurinationality and multiculturalism. It is worth mentioning that the continents of Africa, which in the case, provided hand labor to Latin American colonization, and Asia also experienced this sad scenario of domination in a later phase of the colonial process, so also they are in the battle for restructuring of social values and the cultural exchange, establishing, in this way, a bond with Latin America. In this thematic line, this dissertation, through the emphasis on constitutional and anthropological studies, is intended to show the innovations offered by Equatorian and Bolivian (whose societies are markedly heterogeneous) and Brazilian constitutions, and relative to the search for the consolidation of equity and harmonization of social differences, economic and cultural rights of these minorities in each nation. Moreover, it aims to highlight the existence and importance of cultural identity and richness of these minorities as well as the contribution of their cultures to the formation of any national culture so that respect for minority groups is not seen as a duty, but as a great and beautiful act of citizenship, which is a strong framework of democratic spring in which the countries of the New Constitutionalism come continually passing. To achieve this end, the specific objectives are: to study the aforementioned movement and the historical factors that contributed to the insufficiency of constitutional rights of indigenous and Afrodescendents in Latin America and to the consequent battle for these rights, passing through the evolution of the dimensions of rights fundamentals; once the need for constitutional enshrinement of rights for these peoples has been verified, to understand the link with the ideas of equity, harmonization of differences and citizenship; and to select innovations brought by the Constitutions of Bolivia, Ecuador and Brazil in relation to these groups. Regarding to the Methodology, it's mainly used qualitative bibliographic; so that some basic indoctrinators were Afonso; Magalhães, Pastor; Dalmáu, e Wolkmer; Fagundes; and legislative research as well as exploratory, descriptive and pure. It was concluded that the Constitutions of Bolivia and Ecuador have made great strides towards promoting equity and the harmonization of differences between indigenous and afro-descendents, which is possibly even more than the Brazilian Constitution and that it is necessary to make 
these rights concrete through public policies that provide the extension of citizenship to all and through the awareness of the entire national community that national unity is made up of all ethnic groups.

Keywords: New Latin American Democratic Constitutionalism. Inclusion of minorities. Equator. Bolivia. Brazil.

\section{INTRODUÇÃO}

Atualmente, diante dos frequentes e intensos estudos, debates e ações, tanto a nível nacional por meio dos direitos e garantias constitucionais, como a nível mundial através, por exemplo, da UNESCO (Organização das Nações Unidas para a Educação, a Ciência e a Cultura) e da Rede pelo Constitucionalismo Democrático acerca do enaltecimento e da realização da democracia, dos direitos fundamentais, dos princípios da dignidade da pessoa humana, equidade e igualdade entre todos assim como da inclusão social, econômica e cultural de grupos étnicos, pode até causar a impressão de que seja óbvio que essas questões sejam indiscutivelmente importantes e, por isso, obrigatoriamente devam ser asseguradas de maneira equitativa a todo ser humano. No entanto, faz-se necessário relembrar que esse progresso custou um longo período de lutas por respeito ao multiculturalismo e pelo reconhecimento e exercício desses direitos, pois, lamentavelmente, a História da humanidade, em diversos episódios, revela exatamente o contrário: a existência de regimes autoritários que oprimiram grande parte daqueles que estavam sob o seu domínio. E, ainda hoje, índios ${ }^{2}$ e afrodescendentes permanecem numa luta contínua pela plena aplicação de seus direitos.

Nesse sentido, o presente artigo objetiva tratar do movimento do Novo Constitucionalismo Democrático Latino-Americano por certas óticas das Constituições do Equador (2008) e da Bolívia (2009), em paralelo com a Constituição Brasileira (1988), à busca de maior inclusão social, econômica e cultural de povos indígenas e afrodescendentes, como forma de equidade e harmonização das diferenças assim como extensão da cidadania.

\footnotetext{
${ }^{2}$ Termo conforme ementa da Lei no 6.oor, de 19 de dezembro de 1973: Estatuto do Índio (BRASIL, 1973).
} 
A escolha do tema adveio da discussão na disciplina de Direito Constitucional I da Graduação e da opção da elaboração de artigo com a temática em questão para fins de avaliação.

Quanto à relevância do presente trabalho, do ponto de vista científico, decorre da proposta em contribuir com os estudos acadêmicos acerca do Novo Constitucionalismo Democrático Latino-Americano por certas óticas constitucionais à busca de maior inclusão de povos afrodescendentes e indígenas como forma de equidade e harmonização das diferenças assim como extensão da cidadania. A relevância acadêmica encontra-se no fim de incrementar a discussão do referido movimento em face de documentos constitucionais, povos afrodescendentes e indígenas e ideias como equidade, harmonização das diferenças e cidadania. Socialmente, a importância deve-se à identificação do citado movimento em constituições latino-americanas em prol de alguns dos principais povos formadores dos países e nações relativos às respectivas constituições, no contexto de equidade, harmonização das diferenças e cidadania.

A respeito da problematização, em geral, quais os aspectos do Novo Constitucionalismo Democrático Latino-Americano? Em que consistem os fatores históricos que contribuíram para a insuficiência de direitos constitucionais de afrodescendentes e indígenas na América Latina e para a consequente batalha por esses direitos, passando pela evolução das dimensões dos direitos fundamentais? Constatada a necessidade de consagração constitucional de direitos para esses povos, qual o vínculo com as ideias de equidade, harmonização das diferenças e cidadania? Quais exemplos de inovações trazidas pelas Constituições da Bolívia, Equador e Brasil em relação a esses grupos?

Desse modo, o objetivo geral consiste em analisar o movimento do Novo Constitucionalismo Democrático Latino-Americano por certas óticas das Constituições do Equador (2008) e da Bolívia (2009), em paralelo com a Constituição Brasileira (1988), à busca de maior inclusão social, econômica e cultural de povos indígenas e afrodescendentes, como forma de equidade e harmonização das diferenças assim como extensão da cidadania. Para alcançar esse fim, os objetivos 
específicos delinearam-se na seguinte ordem: estudar o mencionado movimento; assim como os fatores históricos que contribuíram para a insuficiência de direitos constitucionais de indígenas e afrodescendentes na América Latina e para a consequente batalha por esses direitos, passando pela evolução das dimensões dos direitos fundamentais; constatada a necessidade de consagração constitucional de direitos para esses povos, compreender qual o vínculo com as ideias de equidade, harmonização das diferenças e cidadania; e selecionar inovações trazidas pelas Constituições da Bolívia, Equador e Brasil em relação a esses grupos.

Em correspondência aos objetivos, na parte primeira, estuda-se o Novo Constitucionalismo Democrático Latino-Americano. $\mathrm{Na}$ segunda, estudam-se os fatores históricos que contribuíram para a insuficiência de direitos constitucionais de afrodescendentes e indígenas na América Latina e para a consequente batalha por esses direitos, passando pela evolução das dimensões dos direitos fundamentais. $\mathrm{Na}$ terceira, constatada a necessidade de consagração constitucional de direitos para esses povos, procura-se a compreensão de qual o vínculo com as ideias de equidade, harmonização das diferenças e cidadania bem como a seleção de exemplos de inovações trazidas pelas Constituições da Bolívia, Equador e Brasil em relação a esses grupos.

No tocante à Metodologia, emprega-se pesquisa qualitativa bibliográfica e legislativa preponderantemente. A abordagem qualitativa, sem preocupação com representatividade numérica estatística, especificamente bibliográfica é composta por doutrina, como livros e artigos acadêmicos; majoritariamente de Direito Constitucional. A legislativa centra-se nas mencionadas constituições. Outros materiais bibliográficos, e legislativos, por exemplo, são utilizados para fins de diversificação de fontes e de breve abordagem de assuntos tangenciados pelos objetivos geral e específicos. Investigou-se em acervo bibliográfico pessoal e páginas especializadas da rede mundial de computadores, principalmente da Casa Civil.

Trata-se, ainda, de pesquisa exploratória e descritiva, objetivando a explicação e descrição do problema, possibilitando contribuição a estudos outros e, quanto à utilização dos resultados, pura, buscando a ampliação de conhecimentos do tema. 
Almeja-se que, assim como a discussão acadêmica fomentou o trabalho, este ajude a impulsionar outras pesquisas a respeito da temática.

\section{NOVO CONSTITUCIONALISMO DEMOCRÁTICO LATINO- AMERICANO}

Analisando-se os recentes e extensos textos constitucionais da República da Colômbia (1991), da República Bolivariana da Venezuela (1999), da República do Equador (2008) e do Estado Plurinacional Bolívia (2009), percebem-se, nitidamente, as conquistas provenientes do processo de redemocratização ocorrido no final do século XX nesses Estados, os quais procuraram firmar-se como Estados Democráticos de Direito, também conhecidos como Novos Estados de Direito ou Estados Constitucionalistas.

Como se trata de Estado de Direito, tem-se o Estado limitado pela lei, uma das mais fortes expressões do Direito, mas agora, sob uma perspectiva não somente legalista, como no Estado Legalista ou Velho Estado de Direito, mas democrática e, portanto, ligada à legitimidade (basicamente, é a aprovação dos textos legais pelos critérios morais de justiça da comunidade popular) e à efetividade da Constituição nos casos concretos. Dessa forma, as normas constitucionais, predominantemente, passam a ter estrutura de normas-princípios, que não são mais meras orientações ao legislador, mas possuem força normativa, vinculante, ao ter a possibilidade de consagrar um extenso rol de valores basilares de direitos fundamentais.

Em meio a essa efervescência democrática, emana, através do pioneirismo da Constituição da Colômbia de 199ı, o ativo movimento do Novo Constitucionalismo Latino-Americano, assim conceituado:

O Novo Constitucionalismo constitui-se em uma teoria de avanço democrático da Constituição, no qual o conteúdo desta deve expressar, nos limites de suas possibilidades, a vontade soberana de seu povo, o reconhecimento de sua identidade, de sua consciência cultural, dos valores que almejam preservar e da sua melhor forma de organização social e política, cuja prática deverá ser alcançada por meio de mecanismos de participação popular direta, da garantia dos direitos fundamentais, do procedimento de controle de constitucionalidade promovido pelos cidadãos e da criação de regras que limitem os poderes políticos, econômicos, sociais e culturais. (PASTOR; DALMÁU, zori apud FREITAS; MORAES, 2013, p. 13). 
De acordo com Pastor e Dalmáu (2011, p. 14), os elementos formais dessas constituições são: a necessidade (exigibilidade da concretude de políticas eficazes em torno das necessidades fundamentais), a originalidade (conteúdo inovador), a amplitude (textos extensos), a complexidade (conjugação de elementos tecnicamente complexos com uma linguagem acessível) e a rigidez (exigência de um processo legislativo especial para a modificação do texto constitucional, mais burocrático do que o exigido para a elaboração ou modificação das normas infraconstitucionais). Já os materiais são a legitimidade como já explanado, a profusão de direitos (especialmente aqueles que promovam a integração social de minorias, como índios, afrodescendentes e inclusive crianças, jovens e adultos carentes), o caráter normativo e superior da Constituição frente ao resto do ordenamento jurídico (daí a rigidez constitucional e o controle de constitucionalidade, segundo o qual toda a legislação infraconstitucional deve estar em conformidade com a matéria dos princípios constitucionais), a necessidade de superar as desigualdades econômicas e sociais (incorporação de modelos econômicos que conciliem a iniciativa privada e a economia comunitária) bem como a compatibilização da integração com a soberania latino-americana, o que lembra a proposta do Pan-americanismo de Símon Bolívar.

Portanto, o Novo Constitucionalismo, além de um movimento políticojurídico em si, é também uma análise teórica que tem por objeto de estudo as mencionadas Constituições, resultantes de intensas reivindicações populares por um Direito de caráter garantista, limitativo de poderes em favor de um equilíbrio entre eles e promotora de uma reaproximação entre legitimidade e legalidade, entre o cidadão e o governo.

Outro estudioso no assunto, Antônio Carlos Wolkmer, em coautoria com Lucas Machado Fagundes, reflete sobre esse papel do movimento em questão como objeto de estudos constitucionais, principalmente na América Latina:

[...] examina-se o panorama do que vem a ser esse constitucionalismo "novo", emancipatório" ou "transformador" que está ocorrendo majoritariamente nos países andinos, o qual tem sido a mais recente faceta no estudo do direito constitucional, mexendo nas esferas de poder político e na ordem do Estado de Direito [...] fator diferenciado para a cultura constitucional nas suas várias etapas históricas. (WOLKMER; FAGUNDES, 2011, p. 378). 
Nesse sentido de transformação, o Novo Constitucionalismo abarca uma série de inovações, dentre as quais se enfoca a busca de equidade e de harmonização das diferenças na realidade social, econômica e cultural no que tange a povos marginalizados historicamente, a exemplo dos indígenas e dos afrodescendentes.

\section{BATALHA HISTÓRICA}

\section{I Passado colonizador e seus reflexos}

Toda essa fúria democrática e reconhecimento de direitos para os grupos marginalizados resultaram de uma soma de fatores históricos. Em relação à América Latina, sua História revela um passado colonizador de exploração, no qual Espanha e Portugal, as metrópoles, no século XVI, durante as Grandes Navegações e o colonialismo, dominaram o território, inicialmente buscando metais preciosos, extraindo a matéria-prima e escravizando os nativos sob a alegação de expandir a fé católica no mundo:

[...] Nela até agora não pudemos saber que haja ouro nem prata... porém a terra em si é de muitos bons ares assim frios e temperados como os de Entre-Doiro-e-Minho... E em tal maneira é graciosa que, querendo-a aproveitar dar-se-á nela tudo por bem das águas que tem, porém o melhor fruto que nela se pode fazer me parece que será salvar esta gente [...]. (CARTA DE PERO VAZ DE CAMINHA).

Posteriormente, quando os jesuítas iniciaram o processo de catequese dos indígenas, os europeus investiram no sistema de plantation (monocultura voltada para o mercado externo através do plantio em latifúndio e da mão de obra escravizada africana).

$\mathrm{Na}$ colonização da África e da Ásia (colonialismo contemporâneo ou neocolonialismo, nos séculos XIX e XX), realizada, por exemplo, por potências europeias e pelos Estados Unidos numa corrida imperialista por territórios, matériaprima, mão de obra barata e mercado consumidor, também houve opressão sobre os nativos, mas o pretexto dessa vez seria levar o progresso científico e tecnológico das metrópoles para suas colônias.

Ambas as justificativas de expansão do catolicismo e do progresso tecnológico embasaram-se em ideologias científicas em voga principalmente na época do 
Imperialismo para elevarem a "raça" branca e a cultura europeia sobre a latinoamericana, asiática e a africana, consideradas primitivas e atrasadas pelos colonizadores, como pelo fato de os nativos viverem seminus, de praticarem antropofagia, de desconhecerem sua religião e o sistema capitalista e de só extraírem da natureza o necessário para sobreviver. A teoria do darwinismo social de Herbert Spenser, por exemplo, aplicava o darwinismo biológico às sociedades, isto é, havia grupos humanos mais evoluídos que outros. Já segundo o determinismo biológico e geográfico, as diferenças genéticas e geográficas (respectivamente) são determinantes das diferenças culturais e, portanto, da atribuição de características positivas ou negativas inatas a "raças". Assim, os europeus consideravam-se mais evoluídos e detentores inatos de qualidades positivas em relação aos povos colonizados por eles.

Assim, a aculturação e o etnocídio relativos aos nativos, marcadamente pela imposição do idioma, da religião e dos costumes dos colonizadores bem como a escravização dos africanos, os quais também eram proibidos de manifestar suas crenças (motivo pelo qual procuravam praticar o sincretismo religioso) relegaram esses dois grupos étnicos à marginalização social, econômica e cultural. Entretanto, contra esse método colonizador, emergiu certa resistência, embora não suficiente para coibir plenamente a opressão sobre os indígenas:

O debate sobre o direito dos indígenas na América Latina remonta ao século XVI, quando o frei Bartolomé de Las Casas tentou construir uma teoria pacifista e de reconhecimento da diversidade cultural. Las Casas denunciou o discurso a respeito da inferioridade dos índios como um artifício para viabilizar os interesses de conquista ocidentais. [...] Combatia a escravização dos índios e afirmava a possibilidade de evangelizá-los sem o uso da violência. [...] Seu principal opositor foi o jurista Juan Ginés de Sepúlveda, para quem os habitantes das terras novas eram seres inferiores [...] que deveriam ser integrados à comunidade cristã pela força ou então eliminados, caso houvesse resistência.[...]. Ainda que a teoria de Las Casas tenha sido oficialmente acolhida [pela Coroa Espanhola], [...] reconheceram-se seus usos e costumes e as autoridades indígenas, desde que não afetassem a "lei humana e divina", a ordem econômica colonial e a religião católica. O domínio português não foi muito diferente. Ainda que houvesse várias normas proibindo a escravidão dos indígenas, o esforço de submetê-los ao trabalho produtivo em benefício da colônia gerava sua desagregação. (RODRIGUES PINTO).

Essa situação ultrapassou o período colonizador opressor visto que, mesmo após as independências políticas, esses povos não tiveram oportunidades nem 
perspectivas de melhora, já que a classe dominante passou do colonizador para a elite nacional, e permaneceu o clima de inferioridade de suas culturas, discriminação e racismo, isto é, sem respeito à diversidade cultural que deveria compor toda a unidade cultural do país. Essa situação contrapõe-se à ideia de que:

[...] quando um país é libertado de um regime colonialista, torna-se livre para descobrir e desenvolver sua própria identidade nacional [...] e uma minoria racial, quando é libertada da discriminação, fica livre para desfrutar de respeito e dignidade própria. (STOTT, 1997, p. 57).

Porém, nas últimas décadas, estudos sociais e antropológicos vêm afirmando que não existem culturas superiores umas as outras, mas sim diferentes e que todas devem ser respeitadas. Confúcio já enunciava que a natureza dos homens é a mesma, são seus hábitos que os mantêm separados (LARAIA, 2007, p. Io).

Segundo outro autor:

Raça é uma ideia absurda! São as questões culturais, no entanto, que dão unidade à identidade étnica. Determinismo biológico é uma categoria sem fundamento científico. Existiu para fomentar movimentos racistas [...] A identidade, porém, acompanha a diferença, pois são justamente nas relações entre etnias diferentes que as identidades se projetam [...] que melhor observamos as especificidades culturais da etnia. (BRITO, 20II, p. 42-43).

Aduz ainda UNESCO | ONU Brasil assim como Laraia (2007, p. 18) ao comentar uma declaração redigida por antropólogos sob os auspícios da UNESCO, que as diferenças entre os povos explicam-se pelas suas histórias culturais, e não por aparatos biológicos ou geográficos, e que a faculdade de aprender (a racionalidade), e a plasticidade são inatas a todos os seres humanos e, assim, fatores determinantes da evolução de toda a espécie humana.

\subsection{Redemocratização}

Outro fator histórico envolve a influência do crescente fenômeno da globalização e a implantação de regimes militares principalmente na América Latina no século $\mathrm{XX}$, quando a classe dominante mais uma vez esqueceu os grupos já historicamente excluídos, fomentando a busca por uma redemocratização voltada para a realidade interna, outra marca do Novo Constitucionalismo.

Fatores como patrimonialismo, latifúndio, privatização dos bens nacionais, ausência de distribuição de riquezas, inexperiência com governos 


\begin{abstract}
democráticos mais apropriados para a região, importação de valores sociojurídicos adequados, dificuldades legais e políticas de se coibir abusos de poder, dificuldade de uma integração latino-americana ou de uma economia que trouxesse benefícios a todos, e a presença de um militarismo persistente, comprovaram não apenas os problemas internos de se romper com as elites políticas e econômicas que impediam a ampliação dos benefícios democráticos, como também demonstravam uma dependência maior dos países latino-americanos a uma ordem democrática mais globalizada, que precisava ser modificada para atender aos interesses e valores locais. (FREITAS; MORAES, 2013, p. 12).
\end{abstract}

O processo colonialista pelo qual a América Latina passou reflete-se, em maior ou menor grau, no fato de incorporar-se ao mundo subdesenvolvido, buscando reagir contra um modelo político-democrático imposto, por exemplo, pelo neoliberalismo, que não atende adequadamente às demandas dos povos indígenas e africanos no território latino-americano.

\title{
3.3 Dimensões dos Direitos
}

Paralelamente a todos esses fatos, desenrolou-se a famosa evolução dos direitos fundamentais, que são normas jurídicas ligadas à ideia da pessoa humana e de limitação do poder, positivadas no plano constitucional de determinado Estado de Direito, os quais, por sua importância axiológica, fundamentam e legitimam todo o ordenamento (MARMELSTEIN, 2008, p. 20). Nessa evolução, o clamor pelo princípio da igualdade, pela extensão de "benefícios a todos" assumiu um papel preponderante ainda que sob facetas distintas.

O primeiro momento dessa historicidade dos direitos fundamentais coincidiu com o nascimento do Estado Liberal no contexto das revoluções liberais burguesas (como a Inglesa e a Francesa) dos séculos XVII e XVIII, em que se aspirava a uma limitação do poder do Estado, à sua abstenção (prestação negativa) nos planos político e econômico, pois o foco eram os direitos individuais, como a liberdade, igualdade, propriedade privada e segurança, sendo que essa igualdade era apenas formal (simplesmente perante a lei) haja vista que a classe dominante, a burguesia capitalista, só privilegiava seus próprios interesses (MAGALHÃES FILHO, 20II, p. 152). 
Como reação a essa fase, começou a surgir o Estado Social no século XX, principalmente por influência dos protestos da Igreja Católica em prol da humanização capitalista e pelo marxismo, que defendia uma igualdade material, econômica, a ser conquistada inicialmente pela classe proletária para depois dissolver-se por toda a sociedade (MAGALHÃES FILHO, 20II, p. 153). Agora, deveria haver uma prestação positiva por parte do Estado para assegurar os direitos sociais, a exemplo do direito à educação, à saúde e ao trabalho, bem como os econômicos e culturais, os quais passariam a incluir os direitos fundamentais.

Analisando-se essas duas dimensões de direitos, conclui-se que:

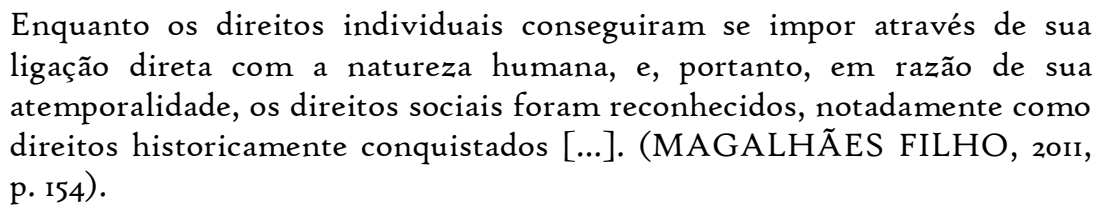

Quanto à terceira dimensão de direitos, no final do século XX e adentrando no XXI, em meio à Revolução Tecnocientífica e à globalização, marcada pelo intercâmbio cultural, político e econômico a nível mundial por intermédio do desenvolvimento dos meios de transporte e comunicação, houve o enfoque à divisão dos direitos em difusos (titular indeterminado, como os direitos ambientais, bem enfatizados pelo Novo Constitucionalismo) e coletivos (titular determinável, como os direitos indígenas) (BRASIL, 1988; MAGALHÃES FILHO, 20II, p. 159; MARMELSTEIN, 2008, p. 48-49, 54, I91, 228; SILVA, 1998, p. 853).

\section{RECONHECIMENTO DE DIREITOS DOS INDÍGENAS E AFRODESCENDENTES}

\section{I Equidade e igualdade}

Essa temática dos direitos sociais, como direito à educação, e dos direitos coletivos relaciona-se intimamente à questão da equidade (do latim aeqŭtas, igualdade) e da harmonização das diferenças entre o restante da comunidade nacional e os índios e afrodescendentes, visto que a atuação desses novos Estados democráticos objetiva considerar as diferenças sociais, culturais e econômicas dos grupos em pauta a fim de reconhecer-lhes cidadania através da positivação de direitos 
e deveres e possibilitar a sua prática por meio de políticas públicas que efetivem a inclusão desses grupos.

Aristóteles já dizia que a democracia [politicia] é o governo onde domina o número, isto é, a maioria, mas também disse que a alma da democracia consiste na liberdade, sendo todos iguais. A igualdade, diz, é o primeiro atributo que os democratas põem como fundamento e fim da democracia. E assim acaba concluindo que toda democracia se funda no direito de igualdade, e tanto mais pronunciada será a democracia quanto mais se avança na igualdade. (SILVA, 1998, p. 133).

$\mathrm{Na}$ verdade, o que iguala todas as pessoas é a própria condição humana comum, o que embasa o princípio da dignidade da pessoa humana de feição universal. Baseando-se nisso, dada a superioridade desse princípio frente às diferenças entre as pessoas, inspiram-se as reivindicações de igualação no plano econômico e social. (MAGALHÃES FILHO, 20II, p. 65). Inclusive, Kant elevou a pessoa humana a valor absoluto, motivo pelo qual ela jamais dever ser tratada como um meio, mas como um fim em si mesmo (MAGALHÃES FILHO, 20II, p I49), meio esse como ocorreu com a escravização dos índios e, predominantemente com os negros africanos.

Além desses argumentos filosóficos, pode-se mencionar a importante contribuição da cultura desses grupos étnicos à formação da história, identidade e cultura dos respectivos países que habitam.

\subsection{Avanços constitucionais}

A seguir, algumas das muitas inovações trazidas pelas Constituições latinoamericanas da Bolívia, do Equador e do Brasil em relação à extensão da cidadania aos grupos afrodescendentes e indígenas.

As novas constituições da Bolívia e do Equador do ano de 2008 são uma grande novidade para o Direito, pois têm o potencial de significar uma ruptura com o modelo estatal moderno. Da uniformização e unificação para não falar na intolerância religiosa e cultural -, elementos estes que forjam a base valorativa do Estado-nação advindo da tradição europeia, o Estado Plurinacional pretende fornecer novos paradigmas não somente em termos de organização social, mas também atender às demandas dos povos e nações historicamente marginalizados no processo "civilizatório" americano, africano e asiático. (AFONSO; MAGALHÃES, 2011, p. 263). 


\subsection{Bolívia}

Como já foi dito, a sociedade boliviana é bastante heterogênea. Sua população étnica é composta majoritariamente de ameríndios (quéchuas e aimarás, de origem inca, guaranis...). Pequenas porcentagens, entre $10 \%$ e $20 \%$, representam euro e afrodescendentes e europeus. Falam-se mais de trinta línguas indígenas (pois cerca de trinta e seis povos originários habitam o país), sendo que várias delas, como a língua quéchua e o aimará, juntamente com o Espanhol, são oficiais (BOLÍVIA SUA PESQUISA). Como se percebe, grande é a necessidade de se efetivar o tratamento igualitário dos indígenas e afrodescendentes.

Segundo a matéria Vitória da nova Constituição significa refundação da Bolívia, da Revista Carta Maior, no governo de Evo Morales, que pertence à etnia aimará e em 2005, foi eleito o primeiro presidente indígena na história do país, a Constituição de 2009 foi aprovada por referendo popular com cerca de 60\% dos votos. Os Estados onde o "não" à Constituição foi mais votado foram os chamados "meialua” (Santa Cruz, Pando, Beni e Tarija) localizados no Oriente do país, onde há grande produção de petróleo e gás e onde reside boa parte da elite que se opunha a Morales devido às suas políticas de estatização desses hidrocarbonetos em favor do desenvolvimento econômico nacional, desagradando, assim, o capital internacional.

Artículo Io: Bolivia se constituye en un Estado Unitario Social de Derecho Plurinacional Comunitario, libre,autonómico y descentralizado, independiente, soberano, democrático e intercultural. Se funda en la pluralidad y el pluralismo político, económico, jurídico, cultural y lingüístico, dentro del proceso integrador del país. (CONSTITUCIÓN DE BOLIVIA).

Nesses valores, funda-se a Constituição, como disse Evo Morales no dia do resultado do referendo: "Hoje é a refundação da Bolívia (...) termina o colonialismo interno e externo (...) é o fim da grande propriedade" .

Além do referendo à Constituição, os bolivianos também votaram sobre o tamanho máximo que uma propriedade rural poderia ter, sendo a opção de 5.000 hectares a mais votada, desagradando mais uma vez às oligarquias nacionais, pois a nova Constituição, em seu artigo 396, passou a proibir, mas sem efeito retroativo, o latifúndio, considerado por Evo Morales "uma tendência improdutiva da terra" e 
estabelecer que a propriedade deva ter uma função social, termo considerado vago pelos oposicionistas, que alegavam que o governo teria muita liberdade para confiscar as terras em prol dos indígenas, por exemplo, (MORALES apud VITÓRIA DA NOVA CONSTITUIÇÃO SIGNIFICA REFUNDAÇÃO DA BOLÍVIA; VITÓRIA DA NOVA CONSTITUIÇÃO SIGNIFICA REFUNDAÇÃO DA BOLÍVIA).

Enfatizando a questão indígena, têm-se 80 dos $4 \mathrm{II}$ artigos da Constituição (AFONSO; MAGALHÃES, 20II, p. 27ı; CONSTITUCIÓN DE BOLIVIA):

- Direito à autodeterminação dos povos indígenas em terras comunitárias (arts. 2으, 289);

- Propriedade exclusiva sobre os recursos florestais e direitos sobre a terra (art. 393) e os recursos hídricos de suas comunidades (art. 372);

- Reorganização territorial do país, o que garante autonomia às frações territoriais (departamental, regional, municipal e indígena) (art. 268, I);

- Equivalência da justiça indígena à institucionalizada, autorizando povos a julgarem crimes segundo os seus costumes. Dessa forma, cada comunidade indígena têm seu próprio "tribunal", com juízes eleitos entre os moradores. As decisões destes tribunais não podem ser revisadas pela Justiça comum (arts. I89, I e II, I99 a 20I);

- Garantia de cota para parlamentares oriundos de povos indígenas;

- Tribunal Constitucional Plurinacional com membros eleitos pelo sistema ordinário e pelo indígena (arts. I89, III e 205 ao 214). A oposição argumenta que essa medida dividiria o país ao criar duas classes distintas de cidadãos;

- Conselho Eleitoral Plurinacional (arts. 215 ao 219) e representação política (arts. 220 ao 223). Ambas as medidas visam assegurar a representação política dos indígenas;

- Defensoria do Povo, órgão de defesa dos direitos indígenas (art. 229, II);

- Integração dos povos e nações indígenas de todo o mundo (art. 264, II);

- Proteção ao patrimônio cultural tanto de indígenas quanto de afrodescendentes, beneficiando-se a diversidade cultural: 
Artículo 32: El pueblo afroboliviano gozará, en todo lo que les corresponda, de los derechos económicos, sociales, políticos y culturales reconocidos en esta Constitución para las naciones y pueblos indígenas originarios campesinos. (CONSTITUCIÓN DE BOLIVIA).

Acentuando a dimensão plurinacional da Constituição da Bolívia e a proposta do Bem-Viver, sobre a qual se discutirá adiante:

O Bem-viver ou Suma Qumanã oficializou-se como princípio ético-moral da sociedade plural na Constituição Política do Estado da Bolívia de 2009 e no Plano Nacional de Desenvolvimento "Bolívia Digna, Soberana, Produtiva e Democrática para Viver Bem", no contexto de refundação do Estado, marcadamente indígena, anticolonialista e plurinacional. (WOLKMER, 2012, p. 16 apud FREITAS; MORAES, 2013, p. 22).

\subsubsection{Equador}

Segue, basicamente, a mesma linha o Estado Equatoriano, cuja composição étnica também é diversificada: cerca de $55 \%$ de eurameríndios e $25 \%$ de ameríndios como os quíchuas. Europeus e afrodescendentes compõem minorias. Embora o espanhol seja o idioma oficial, também falam-se línguas indígenas, com destaque, mais uma vez, para a quíchua (EQUADOR - SUA PESQUISA).

A Constituição de 2008, com 444 artigos, também foi aprovada por referendo popular (aproximadamente 80\% dos votos), durante a presidência de Rafael Correia e com Alberto Acosta como presidente da Assembleia Nacional Constituinte do Equador, chamada Montecristi (ECUADOR).

\footnotetext{
Artículo Io: Ecuador es un Estado de derecho y la justicia constitucional, unitaria Estado social democrático, soberano, independiente intercultural, plurinacional y Secular [...]. (ECUADOR).
}

Dentre as inovações:

- Resgate dos saberes tradicionais (preâmbulo) que constituem substrato filosófico para outro aspecto (além do democrático) muito relevante ao Novo Constitucionalismo Equatoriano, que é a proposta do Bem-Viver, que objetiva a proteção aos direitos ambientais e a convivência harmônica com a natureza, considerada a mãe de toda a humanidade e sujeito de direitos nas relações processuais. Por exemplo, um rio em processo de degradação devido a uma obra pública pode ser parte numa ação contra o Estado, como foi o caso do rio Wilcabamba no Equador (FREITAS; MORAES, 2013, p. 20). 
[...] um constitucionalismo de feição ecocêntrica [...] tendo como principais centros irradiadores de mudanças, o Equador e a Bolívia, cujas reformas constitucionais recentes [...] a partir da inclusão dos povos indígenas e de outras minorias ético-raciais como atores sociais na atualidade, incorporaram vetustos valores resgatados das raízes pré-colombianas comuns, entre os quais sobressai o respeito à natureza e ao ambiente, vale dizer, o respeito prioritário à vida. (FREITAS; MORAES, 2013, p. 15).

Pelo exposto sobre a composição populacional na Bolívia e Equador e a colação retro, observa-se que os povos indígenas, apesar de seu quantitativo, podem ser considerados minorias (em sentido de efetivação de direitos) assim como os afrodescendentes.

- Reconhecimento do Direito Consuetudinário indígena para a solução de conflitos internos (art. I9I) (ECUADOR), o que se assemelha à liberdade jurisdicional concedida a eles na Bolívia.

A partir dos anos oitenta, as análises antropológicas passaram a [...] ver o direito consuetudinário e o direito estatal não mais como sistemas paralelos, mas como distintas esferas legais que coexistiam numa relação mutuamente constitutiva. [...] Esses povos deverão ter o direito de conservar seus costumes e instituições próprias, desde que eles não sejam incompatíveis com os direitos fundamentais definidos pelo sistema jurídico nacional nem com os direitos humanos internacionalmente reconhecidos. Sempre que for necessário, deverão ser estabelecidos procedimentos para se solucionar os conflitos que possam surgir na aplicação deste princípio. (RODRIGUES PINTO).

- Novamente, proteção ao patrimônio cultural (arts. 377 a 380), reafirmando o que já é assegurado no começo do texto constitucional:

De grande significância para o projeto plurinacional, o texto constitucional reconheceu e incorporou no seio político as culturas e comunidades historicamente excluídas, conforme se depreende da leitura dos artigos io e II: "Os povos $e$ as pessoas indígenas têm direito a pertencer a uma comunidade ou nação indígena, de conformidade com as tradições e costumes da comunidade ou nação que se trate. Não pode haver nenhuma discriminação [...] ao exercício deste direito". (GRIJALVA, 2008, p. 56 apud AFONSO; MAGALHÃES, 2011, p. 272).

- Lei dos Direitos Coletivos dos Povos Negros ou Afro-equatorianos, de 2006, que, inclui normas acerca dos direitos sobre suas terras ancestrais e proteção à identidade cultural, com desenvolvimento econômico, social, cultural e político, além de incorporar seus representantes nas instituições do Estado (ECUADOR). 


\subsubsection{Brasil}

No Brasil, embora sejam minoria numérica em relação ao total da população, os indígenas e afrodescendentes compõem uma considerável parcela da comunidade nacional: o Brasil tem a maior população de origem africana fora da África, e os índios no Brasil somam 896,9 mil pessoas, de 305 etnias, que falam 274 línguas indígenas (CULTURA AFRO-BRASILEIRA - PORTAL BRASIL), revelando um crescimento de $205 \%$ na população indígena do país desde 199I, quando foi feito o primeiro levantamento no modelo atual, segundo dados do Censo de 2010 divulgados pelo Instituto Brasileiro de Geografia Estatística (IBGE REGISTRA CRESCIMENTO DE 205\% NA POPULAÇÃO INDÍGENA...).

A Constituição Federal (BRASIL, 1988), apesar de carente em relação aos direitos autogestão indígena, consagra, por exemplo, no artigo $\mathrm{I}^{\mathrm{o}}$, inciso III, a dignidade da pessoa humana como um dos princípios que regem a República Federativa do Brasil como um Estado Democrático de Direito; no artigo 3으, inciso IV, a promoção do bem de todos sem preconceito de origem, raça ou qualquer outro

tipo de discriminação; no artigo $4^{\circ}$, inciso VIII, e no artigo $5^{\circ}$, inciso XLII, o repúdio ao racismo; no artigo $5^{\text {a }}$, caput, o princípio da igualdade ("Todos são iguais perante a lei sem distinção de qualquer natureza...”); no artigo 210, caput, o respeito aos valores culturais nacionais e regionais; no artigo 210, $\S 2^{2}$, o direito das comunidades indígenas de utilizarem suas línguas maternas e processos próprios de aprendizagem (embora o artigo I3 estabeleça que o idioma oficial no Brasil seja o português); nos artigos 215 e 216, a proteção aos direitos culturais, com destaque para o artigo 215, § Iํㅜ “O Estado protegerá as manifestações das culturas populares, indígenas e afrobrasileiras...”, e os artigos 23 I e 232 destinam-se exclusivamente ao Direito Indígena através de um caráter mais tutelar, enquanto nas constituições equatoriana e boliviana, esse caráter é mais emancipatório.

A legislação brasileira (BRASIL, 1973, 2010, 2003) engloba também o Estatuto do Índio (Lei no 6.ooI, de I9 de dezembro de 1973; “Art. Io: Esta Lei regula a situação jurídica dos índios ou silvícolas e das comunidades indígenas, com o propósito de preservar a sua cultura e integrá-los, progressiva e harmoniosamente, à comunhão 
nacional"), além do Estatuto da Igualdade Racial (Lei $\mathrm{n}^{\mathrm{O}}$ 12.288, de 20 de julho de 2010; “Art. I ${ }^{\circ}$ : Esta Lei institui o Estatuto da Igualdade Racial, destinado a garantir à população negra a efetivação da igualdade de oportunidades, a defesa dos direitos étnicos individuais, coletivos e difusos e o combate à discriminação e às demais formas de intolerância étnica”). Além disso, a Lei no 10.639 , de 9 de janeiro de 2003, “altera a Lei no 9.394, de 20 de dezembro de 1996, que estabelece as diretrizes e bases da educação nacional, para incluir no currículo oficial da Rede de Ensino a obrigatoriedade da temática 'História e Cultura Afro-Brasileira', e dá outras providências."

$\mathrm{Na}$ esfera internacional, também existem avanços:

\begin{abstract}
Atualmente, os documentos internacionais mais específicos que abordam o direito dos indígenas [...] são a Convenção para a Prevenção e Punição do Delito de Genocídio (1948), a Convenção Internacional sobre a Eliminação de todas as formas de Discriminação Racial (1965), o Convênio i69 da OIT (1989), a Declaração sobre os Direitos das Populações Indígenas (2007) e a Declaração Americana sobre os Direitos dos Povos Indígenas (1997). (RODRIGUES PINTO).
\end{abstract}

Retornando ao Brasil, o país está no caminho que já está sendo percorrido pela

Bolívia e Equador em uma espécie de integração, relacionando-se à meta da República Brasileira, presente no parágrafo único do artigo $4^{\circ}$ da Constituição, de buscar a integração dos povos da América Latina através dessas medidas em prol da cidadania dos povos indígenas e afrodescendentes:

[...] A década de noventa do século XX foi marcada por muitos conflitos interétnicos e turbulências de fundo cultural, mas também representou o período de maior avanço nas legislações nacionais e internacionais no que tange ao reconhecimento do direito à autodeterminação dos povos, principalmente se levarmos em consideração as Constituições nacionais da América Latina. (RODRIGUES PINTO).

\title{
CONSIDERAÇÕES FINAIS
}

Diante de todo o exposto, conclui-se que as Constituições da Bolívia e do Equador muito progrediram no sentido de se promover a equidade e a harmonização das diferenças sociais, econômicas e principalmente culturais dos indígenas e afrodescendentes, sendo possível ainda mais que a Constituição brasileira, haja vista que a Bolívia e o Equador pertencem ao Novo Constitucionalismo Democrático 
Latino-Americano. Aqueles povos, ainda que majoritários nas populações boliviana e equatoriana fossem historicamente marginalizados pela colonização europeia e por regimes elitistas, antidemocráticos e restritivos de direitos. Esse gradativo processo de inclusão das minorias, buscando fazer jus aos princípios da igualdade e da dignidade da pessoa humana, por exemplo, vem desde uma ebulição de ideologias que combatiam o racismo e outras formas de discriminação, passando pela evolução dos direitos fundamentais e chegando, atualmente, a um grande esplendor através das propostas de redemocratização do Novo Constitucionalismo Latino-Americano.

As dificuldades durante a pesquisa consistiram no recorte temático diante de tantas constituições e povos indígenas e afrodescendentes na América Latina e, posteriormente, na análise de constituições em idiomas distintos (assim como alguns outros textos e inseridas em contextos ímpares e de povos dotados de complexidade e identidade próprias. Adicione-se o início da confecção do artigo após contato relativamente recente com o assunto e no começo da Graduação. No entanto tais dificuldades muito instigaram a sede pelo aperfeiçoamento.

Outrossim, o tema demandou diversidade de fontes, do que se demonstra a inafastável interdisciplinaridade, principalmente entre o Direito Constitucional nacional e internacional, o Direito Indígena, a Antropologia e, assim, a Antropologia Jurídica além da História Geral e do Brasil e a Geografia Humana.

Portanto, é necessário que haja não só o mero reconhecimento constitucional de direitos às minorias étnicas ou a simples e enfadonha tolerância de um grupo em relação ao outro, mas sim uma efetiva concretude desses direitos por meio de políticas públicas que proporcionem condições para a extensão de cidadania a todos os membros do Estado e por meio da conscientização de toda a comunidade nacional de que a unidade nacional, incluindo-se toda a identidade cultural de um país, é composta por todos os variados e numerosos grupos étnicos, devendo-se respeitar suas diferenças, isto é, manter uma relação intercultural de alteridade e uma convivência harmônica. Dessa maneira, contribuir-se-á para uma autêntica consolidação do Estado Democrático de Direito. 


\section{REFERÊNCIAS}

AFONSO, Henrique Weil; MAGALHÃES, José Luís Quadros de. O estado plurinacional da Bolívia e do Equador: matrizes para uma releitura do direito internacional moderno. Revista Brasileira de Direito Constitucional, [S. l.], n. i7, p. 263-276, jan./jun., 20II.

BOLÍVIA - SUA PESQUISA. Bolívia - sua pesquisa. Disponível em: 〈http://www.suapesquisa.com/paises/bolivia/> Acesso em: 20 mai. 2014.

BRASIL. Constituição da República Federativa do Brasil de 1988. Brasília, DF, 5 out. 1988.

em: <www.planalto.gov.br/ccivil_03/constituicao/constituicao.htm〉. Acesso em: 19 mai. 2014.

BRASIL. Lei no 6.oor, de I9 de dezembro de 1973. Dispõe sobre o Estatuto do Índio. Brasília, DF, 2I dez. 1973. Disponível em: <www.planalto.gov.br/ccivil_03/leis/16oor.htm>. Acesso em I9 mai. 2014.

BRASIL. Lei no Io.639, de 9 de janeiro de 2003. Altera a Lei no 9.394, de 20 de

dezembro de 1996, que estabelece as diretrizes e bases da educação nacional, para incluir no currículo oficial da Rede de Ensino a obrigatoriedade da temática "História e Cultura Afro-Brasileira", e dá outras providências. Brasília, DF, ıo jan. 2013. Disponível em: <www.planalto.gov.br/ccivil_03/leis/2003/1ro.639.htm>. Acesso em I9 mai. 2014.

BRASIL. Lei no 12.288, de 20 de julho de 2010. Institui o Estatuto da Igualdade Racial; altera as Leis nos 7.716, de 5 de janeiro de 1989, 9.029, de 13 de abril de 1995, 7.347, de 24 de julho de 1985, e 10.778, de 24 de novembro de 2003. Disponível em: <www.planalto.gov.br/ccivil_03/_Ato2007-2010/2010/.../L12288.htm>. Acesso em 19 mai. 2014 .

CARTA DE PERO VAZ DE CAMINHA. Carta de Pero Vaz de Caminha. Disponível em: $\langle$ http://objdigital.bn.br/Acervo_Digital/Livros_eletronicos/carta.pdf $\rangle$. Acesso em I9 mai. 2014. 
BRITO, Antônio José Guimarães. Etnicidade, alteridade e tolerância. In: COLAÇO, Thais Luzia. Elementos de Antropologia Jurídica. São Paulo: Conceito Editorial, 20II. V. I. P. 4I-57.

CONSTITUCIÓN DE BOLIVIA. Constitución de Bolivia. Disponível em: 〈http://www.transparencialegislativa.org/wpcontent/uploads/2013/o4/Constitucio $\%$ CC\%8In-Bolivia.pdf $>$. Acesso em 20 mai. 2014.

CULTURA AFRO-BRASILEIRA - PORTAL BRASIL. Cultura afro-brasileira Portal Brasil. Disponível em: 〈http://www.brasil.gov.br/cultura/2009/ro/culturaafro-brasileira>. Acesso em I9 mai. 2014.

ECUADOR: 2008 CONSTITUTION IN ENGLISH. Ecuador: 2008 Constitution in English. Disponível em: 〈http://pdba.georgetown.edu/Constitutions/Ecuador/englisho8.html〉. Acesso em 20 mai. 2014.

EQUADOR - SUA PESQUISA. Equador - sua pesquisa. Disponível em: $\langle$ http://www.suapesquisa.com/paises/equador/>. Acesso em 20 mai. 2014.

FREITAS, Raquel Coelho de; MORAES, Germana de Oliveira. O Novo Constitucionalismo Latino Americano e o giro ecocêntrico dos Andes: os direitos de Pachamama e o bem-viver na Constituição do Equador (Sumak Kawsay) e da Bolívia (Suma Qamaña). In: Unasul e Novo Constitucionalismo Latino-Americano. Curitiba: CRV, 2013. P. II-25.

IBGE REGISTRA CRESCIMENTO DE 205\% NA POPULAÇÃO INDÍGENA... IBGE registra crescimento de $205 \%$ na população indígena... Disponível em: $<$ http://revistaepoca.globo.com/Sociedade/noticia/2012/o8/populacao-indigena-nobrasil-cresceu-205-em-duas-decadas.html>. Acesso em I9 mai. 2014.

LARAIA, Roque de Barros. Cultura, um conceito antropológico. $2 \mathrm{I}^{\mathrm{a}}$ ed. Rio de Janeiro: Jorge Zahar, 2007. V. I.

MAGALHÃES FILHO, Glauco Barreira. Hermenêutica e unidade axiológica da Constituição. $4^{\underline{a}}$ ed. Belo Horizonte: Del Rey, 20II. V. I.

MARMELSTEIN, George. Curso de Direitos Fundamentais. São Paulo: Atlas, 2008. V. I. 
PASTOR, Viciano Roberto; DALMAU, Rúben Martínez. El nuevo constitucionalismo latinoamericano: Fundamentos para una construcción doctrinal. In: Revista General de Derecho Público Comparado, [S. l.], n. 9, p. I-24, 2011.

RODRIGUES PINTO, Simone. Reflexões sobre pluralismo jurídico e direitos indígenas na américa do sul. Disponível em: $<$ http://www.sociologiajuridica.net.br/numero-6/253-reflexoes-sobre-pluralismojuridico-e-direitos-indigenas-na-america-do-sul-simone-rodrigues-pinto〉. Acesso em 20 mai. 2014.

SILVA, José Afonso da. Curso de Direito Constitucional Positivo. $15^{\underline{a}}$ ed. São Paulo: Malheiros, 1998. V. I.

STOTT, John. Ouça o Espírito, ouça o mundo. São Paulo: ABU Editora Teo, 1997. V. I.

UNESCO | ONU BRASIL. UNESCO | ONU Brasil. Disponível em: 〈http://www.onu.org.br/onu-no-brasil/unesco>. Acesso em I7 mai. 2014. VITÓRIA DA NOVA CONSTITUIÇÃO SIGNIFICA REFUNDAÇÃO DA BOLÍVIA. Vitória da nova Constituição significa refundação da Bolívia. Disponível em: <http://www.cartamaior.com.br/?/Editoria/Internacional/-Vitoria-da-novaConstituicao-significa-refundacao-da-Bolivia-/6/I4735> Acesso em: 20 mai. 2014. WOLKMER, Antonio Carlos; FAGUNDES, Lucas Machado. Tendências contemporâneas do constitucionalismo latino-americano: Estado Plurinacional e pluralismo jurídico. Pensar, Fortaleza, v. 16, n. 2, p. 371-408, jul./dez. 2011. 